ББК 67.402

\title{
ФОРМА СТРАТЕГИЧЕСКОГО ПЛАНИРОВАНИЯ РОССИЙСКОЙ ЭКОНОМИКИ - ГОСУДАРСТВЕННО-ЧАСТНОЕ ПАРТНЕРСТВО: К ВОПРОСУ ПРАВОВОГО РЕГУЛИРОВАНИЯ
}

\author{
(c) 2021 Щукина Татьяна Владимировна \\ доктор юридических наук, доцент \\ ведущий научный сотрудник сектора административного права и процесса \\ Институт государства и права РАН, Россия, Москва
}

Предметом настоящей статьи выступает исследование новых форм и инструментов стратегического планирования российской экономики. Тема статьи отражает вопросы правового регулирования государственно-частного партнерства. Целью настоящей статьи является выявление особенностей возникновения, функционирования и поддержки государственно-частного партнерства на современном этапе социально-экономического развития, места и роли государства в этом процессе. Методологию данной работы составили сравнительный, формально-юридический, аналитический методы. Результаты работы - это формулирование новых форм стратегического планирования развития экономической деятельности в Российской Федерации. Область применения результатов работы включает в себя политику стратегического планирования экономики в форме государственночастного и муниципально-частного партнерства.

Ключевые слова: государственно-частное, муниципально-частное партнерство, публичный интерес.

Правовое регулирование государственночастного партнерства осуществляется федеральным законом от 13 июля 2015 года «O государственно-частном партнерстве, муниципально-частном партнерстве в Российской Федерации и внесении изменений в отдельные законодательные акты Российской Федерации» [1], иными федеральными законами [2] и нормативными правовыми актами РФ [3], нормативными правовыми актами субъектов РФ [4], муниципальными правовыми актами [5].

Вступление в силу федерального закона «O государственно-частном партнерстве, муниципально-частном партнерстве в Российской Федерации и внесении изменений в отдельные законодательные акты Российской Федерации» обозначает новый период в модернизации публичного управления в Российской Федерации, совершенствовании инструментов публичного регулирования бюджетных средств, а также стратегическое обновление возможных результатов государственного управления и его социальных эффектов.

Согласно статье 4 указанного федерального закона государственно-частное партнерство строится на определенных принципах, таких как: [6] открытость и доступность информации о государственно-частном партнерстве, обе- спечение конкуренции, равноправие сторон соглашения и равенство их перед законом, добросовестное исполнение сторонами соглашения обязательств по соглашению, справедливое распределение рисков и обязательств между сторонами соглашения, свобода заключения соглашения.

Субъекты РФ в собственных нормативных правовых актах устанавливают дополнительный перечень принципов, на которых строится государственно-частное партнерство [7]:

- законности, равноправия сторон;

- обеспечения равных условий доступа юридических и физических лиц к участию в партнерстве;

- соблюдения прав и законных интересов сторон партнерства; добросовестного и взаимовыгодного сотрудничества сторон соглашений;

- эффективности использования бюджетных средств при реализации государственночастного партнерства.

Данные принципы подтверждают гражданско-правовой формат соглашения о государственно-частном партнерстве. Несмотря на это, государственно-частное и муниципально-частное партнерства сопряжены в большей степени с публичным интересом.

Он характеризуется наличием обязательно- 
го участника государственно-частного партнерства (публичного партнера) - государства в лице Российской Федерации, субъекта Российской Федерации, муниципального образования и соответствующих уполномоченных органов власти. Публичный партнер - это:

- Российская Федерация, от имени которой выступает Правительство РФ или уполномоченный им федеральный орган исполнительной власти (уполномоченным федеральным органом исполнительной власти может быть любой отраслевой ФОИВ: министерство здравоохранения РФ по медицинским проектам; министерство транспорта РФ в области железнодорожной инфраструктуры; министерство обороны РФ в отношении логистических комплексов для вооруженных сил РФ и т.д. По концессионным соглашениям публичным партнером могут выступать уполномоченная публично-правовая компания, государственная компания (ГК «Автодор» и др.);

- субъект РФ, от имени которого выступает высший исполнительный орган государственной власти субъекта РФ или уполномоченный им орган исполнительной власти субъекта РФ (высший исполнительный орган государственной власти субъекта РФ определяет уполномоченный им орган исполнительной власти в сфере ГЧП. Это может быть профильный департамент (г. Москва), управление инвестиций и международных связей Липецкой области (Липецкая область). Отдельные права и обязанности публичного партнера могут быть переданы публично-правовой компании субъекта РФ (ОАО «Корпорация Развития Липецкой области»);

- муниципальное образование, от имени которого выступает глава муниципального образования или иной уполномоченный орган местного самоуправления в соответствии с уставом муниципального образования.

Характеристикой объектов государственночастного партнерства, обремененных социальной значимостью. К ним относятся:

- объекты здравоохранения, образования, культуры, спорта;

- объекты благоустройства территорий;

- подводные и подземные технические сооружения;

- воздушные суда, аэродромы, аэропорты;

- морские порты, речные порты, морские суда и речные суда;

- объекты железнодорожного транспорта;
- транспорт общего пользования;

- гидротехнические сооружения, объекты по производству, передаче и распределению электрической энергии;

- подводные и подземные технические сооружения, переходы, сооружения связи, линии связи и коммуникации [8];

- мелиоративные системы;

- промышленные объекты, на которых осуществляются обработка, утилизация, обезвреживание, размещение твердых коммунальных отходов;

- объекты трубопроводного транспорта;

- частные автомобильные дороги или участки частных автомобильных дорог, мосты, защитные дорожные сооружения, искусственные дорожные сооружения, производственные объекты;

- имущественные комплексы, предназначенные для производства промышленной продукции;

- объекты производства, первичной и последующей промышленной переработки, хранения сельскохозяйственной продукции [9];

- объекты охотничьей инфраструктуры;

- программы для ЭВМ, базы данных, информационные системы, сайты в информационнотелекоммуникационной сети «Интернет», в состав которых входят такие программы для ЭВМ, базы данных [10];

- объекты информационных технологий и имущество, технологически связанное с одним или несколькими программами для ЭВМ, базами данных;

- совокупность зданий, частей зданий или помещений, предназначенных для автоматизации с использованием программ для ЭВМ и баз данных процессов формирования, хранения, обработки, приема, передачи, доставки информации, обеспечения доступа к ней, ее представления и распространения [11].

В федеральном законе от 13 июля 2015 года «О государственно-частном партнерстве...» недавно действует глава 6.1, посвященная особенностям регулирования отношений, возникающих в связи с подготовкой, заключением, исполнением и прекращением соглашения о ГЧП, объектом которого являются объекты информационных технологий или объекты информационных технологий и технические средства обеспечения функционирования объектов информационных технологий. 
Дифференцируются объекты ГЧП по сферам управления: благоустройство и сопутствующая инженерно-техническая инфраструктура, информационные системы, коммунально-энергетическая сфера, оборона и безопасность страны, промышленная инфраструктура, сельскохозяйственная и охотохозяйственная сферы, социальная сфера. Социально значимые объекты становятся предметом государственно-частного партнерства очень часто. Например, в Ульяновской области нормативно [12] закреплен перечень объектов спорта, создание которых планируется на условиях ГЧП: центр единоборств на территории муниципального образования «город Ульяновск», футбольный манеж на базе стадиона «Мотор» в городе Ульяновск и еще шесть подобных спортивных сооружений. В качестве социально значимых объектов выступают также ледовые дворцы, детские сады, туристические комплексы, медицинские учреждения, бассейны, оздоровительные детские лагеря.

Публичный интерес в государственночастном партнерстве проявляется ярко в процедурах подготовки проекта государственночастного партнерства, принятия решения о реализации проекта государственно-частного партнерства, организации конкурсных процедур для отбора частных партнеров и заключения соглашения о государственно-частном партнерстве. Под проектом государственно-частного партнерства, проектом муниципально-частного партнерства понимается проект, планируемый для реализации совместно публичным партнером и частным партнером на соответствующих принципах.

Публичный партнер обязан рассмотреть данное предложение о реализации ГЧП и принять решение о направлении предложения на рассмотрение в уполномоченный орган в целях оценки эффективности или о невозможности реализации проекта. Решение публичного партнера об этом должно быть мотивированным.

Кроме того, федеральным законом «O государственно-частном партнерстве, муниципально-частном партнерстве в Российской Федерации и внесении изменений в отдельные законодательные акты Российской Федерации» предусматривается процедура оценки эффективности проекта государственночастного партнерства уполномоченным органом на основании следующих критериев:
1) финансовой эффективности проекта, 2) социально - экономического эффекта от реализации проекта. Оценка эффективности проекта оценивается по двум основным направлениям: 1) финансовая эффективность проекта, 2) социальноэкономический эффект от реализации проекта, рассчитанный с учетом целей и задач, определенных в документах стратегического планирования.

По итогам оценок эффективности и сравнительного преимущества проекта государственно-частного партнерства уполномоченный орган утверждает об этом соответствующее заключение. Положительное заключение направляется публичным партнером в Правительство РФ, высший исполнительный орган государственной власти или главе муниципального образования, которые уполномочены принимать решение о реализации проекта ГЧП (МЧП). В этом решении определяются такие важные моменты, как:

- существенные условия соглашения;

- значения критериев эффективности проекта и значения показателей его сравнительного преимущества, на основании которых получено положительное заключение уполномоченного органа;

- вид конкурса (открытый конкурс или закрытый конкурс), а также перечень лиц, которым направляются приглашения принять участие в конкурсе (в случае проведения закрытого конкурса);

- критерии конкурса и параметры критериев конкурса;

- конкурсная документация или порядок и сроки ее утверждения;

- сроки проведения конкурса на право заключения соглашения или в случае проведения совместного конкурса - соглашений.

Во всех случаях, даже без проведения конкурсной процедуры, в решении о реализации проекта ГЧП (МЧП) предусматриваются вопросы, касающиеся существенных условий соглашения о ГЧП (МЧП), и порядка его заключения.

Решение о реализации проекта государственно-частного партнерства, принятого соответствующими органами власти предоставляет право частному партнеру принять участие в конкурсе на заключение соглашения о государственно-частном партнерстве.

Существуют в нормативных правовых актах субъектов РФ дополнительные процеду- 
ры в процессе рассмотрения публичным партнером предложения о реализации проекта государственно-частного партнерства. Так, в Липецкой области [13] предложение отраслевого органа (частного партнера) подлежит рассмотрению Советом по улучшению инвестиционного климата и содействию развитию конкуренции в Липецкой области. Уполномоченный орган в течение 60 дней со дня поступления предложения выносит на рассмотрение Совета вопрос о принятии решения о признании целесообразности реализаций проекта ГЧП и согласовании условий соглашения. По итогам рассмотрения предложения Совет принимает одно из следующих решений:

- о признании целесообразности реализации проекта ГЧП, согласовании условий соглашения и направлении предложения на рассмотрение в уполномоченный орган в целях оценки эффективности и определения его сравнительного преимущества;

- о невозможности реализации проекта на основании предложения.

Решения Совета оформляются протоколом и подписываются председателем.

В Томской области [14] разрабатывается концепция проекта государственно-частного партнерства. В целях принятия решения о реализации проекта ГЧП исполнительные органы государственной власти Томской области осуществляют разработку Концепции, которая утверждается Администрацией Томской области. Концепция включает в себя:

- обоснование возможности и необходимости реализации проекта в соответствии с целями и задачами, установленными в документах стратегического и программно-целевого планирования Томской области;

- параметры реализации проекта: основные технико-экономические показатели проекта, включая предварительную оценку совокупного объема инвестиций, экономической, бюджетной и социальной эффективности проекта, сведения о предполагаемых источниках дохода по проекту, источники финансирования проекта, описание и состав объектов, товаров и (или) услуг, которые будут создаваться или предоставляться в результате реализации проекта, предполагаемые сроки реализации проекта;

- краткое описание основных технологий, выбранных для реализации проекта, предложения по использованию наукоемких, энергос- берегающих, ресурсосберегающих технологий, предварительную оценку воздействия намечаемой деятельности на окружающую среду;

- сведения о предлагаемом месторасположении, составе и имущественном статусе объектов, вовлекаемых в реализацию проекта и характеристики необходимого для реализации проекта земельного участка (участков);

- предварительную оценку рисков и предложения по распределению рисков, с учетом возможного опыта реализации аналогичных проектов на территории РФ или иностранных государств.

После победы в конкурсе частному партнеру разрешается реализовывать условия соглашения о государственно-частном партнерстве, то есть приступить к проектированию и строительству объектов общественной инфраструктуры.

Государственно-частное и муниципальночастное партнерство реализуется в настоящее время в основном в следующих формах: а) концессионного соглашения, б) договора аренды с инвестиционными обязательствами, в) соглашения о ГЧП [15]; г) долгосрочного инвестиционного соглашения; д) контракта жизненного цикла. Нужно отметить, что выделяются и другие формы, в которых может реализовываться ГЧП: государственные контракты, лизинг, соглашения о разделе продукции [16]. Ввиду того, что в реалиях развития ГЧП ни публичные, ни частные партнеры окончательно не определились с конкретными формами этого экономического явления, государственно-частное партнерство моделируется по договоренности партнеров с учетом имеющегося законодательства. Тем более, Гражданский кодекс РФ позволяет выбирать для юридического оформления ГЧП смешанные договоры, поэтому существует некая неопределенность в конкретизации форм ГЧП. В настоящее время частично по этой причине инвестиционные проекты в форме концессионного соглашения превалируют над количеством соглашений о ГЧП (МЧП).

Несколько слов отметим о контракте жизненного цикла как форме государственночастного партнерства. Контракт жизненного цикла обозначен в федеральном законе от 5 апреля 2013 г. N 44-Ф3 «О контрактной системе в сфере закупок товаров, работ, услуг для обеспечения государственных и муниципальных нужд» как контракт, заключаемый в случаях, установленных Правительством РФ. Заказчик 
(публичный партнер) вправе заключить контракт, предусматривающий закупку товара или работы (в том числе при необходимости проектирование, конструирование объекта, который должен быть создан в результате выполнения работы), последующие обслуживание, ремонт и при необходимости эксплуатацию и (или) утилизацию поставленного товара или созданного в результате выполнения работы объекта. В этих обстоятельствах и появляется контракт жизненного цикла.

Рассмотрение контракта жизненного цикла в качестве формы ГЧП связано и с тем, что постановлением Правительства РФ от 28 ноября 2013 г. N 1087 «Об определении случаев заключения контракта жизненного цикла» [17] закреплен предмет данного контракта. Это выполнение работ по проектированию и строительству объектов инфраструктуры, которые совпадают с объектами соглашения о ГЧП (МЧП), а также закупка железнодорожного подвижного состава, транспортных средств метрополитена, внеуличного транспорта, городского наземного электрического транспорта, воздушных судов, морских и речных судов. Проектирование и строительство касаются автомобильных дорог, морских и речных портов, аэродромов, объектов коммунальной инфраструктуры, железнодорожного транспорта, метрополитена, внеуличного транспорта и городского наземного электрического транспорта, объектов в сферах здравоохранения, культуры, социального обслуживания, проживания военнослужащих и членов их семей. Учитывая отсутствие детального правового регулирования контракта жизненного цикла, его следует отличать от обычной закупки товаров, работ и услуг для государственных и муниципальных нужд. Да и сама правовая форма контракта жизненного цикла является неопределенной между государственным (муниципальным) контрактом по закупкам для государственных и муниципальных нужд и соглашением о концессии [18].

В связи с вышесказанным, государственночастное партнерство как форма взаимодействия органов государственной и муниципальной власти по вопросам развития социальной инфраструктуры соответствующей территории обладает рядом положительных черт и эффектов для государства:

1) обеспечение стабильного социального эффекта публичного управления в процессе планомерного и постоянного формирования, реконструкции важных инфраструктурных объектов. Например: объектов водоснабжения и водоотведения, очистки сточных вод; объектов по производству, передаче и распределению тепловой энергии; участков автомобильных дорог; мостов, путепроводов, тоннелей;

2) создание экономически выгодной и финансово оправданной системы эксплуатации комплекса отраслевых объектов транспортной, социальной, коммунальной, энергетической инфраструктуры, позволяющей возвращать вложенные инвестиции в виде выплат за предоставленные услуги;

3) развитие конкурентной среды среди хозяйствующих субъектов, оказывающих услуги по проектированию и строительству инфраструктурных объектов, и повышению качества подобных работ;

4) оптимизация бюджетных расходов, направленных на строительство, реконструкцию и поддержку эксплуатации объектов отраслевой инфраструктуры;

5) возложение ответственности за проектирование, строительство или реконструкцию, эксплуатацию инфраструктурных объектов как в техническом, так и финансовом плане на частного партнера (снижение рисков будущих затрат на эксплуатацию);

6) сохранение серьезной системы контроля публичным партнером исполнения соглашения о государственно-частном партнерстве (исполнения обязательств по соблюдению сроков проектирования, создания объекта соглашения, финансирования создания объекта соглашения, обеспечения соответствия техникоэкономических показателей объекта).

\section{Библиографический список}

1. О государственно-частном партнерстве, муниципально-частном партнерстве в Российской Федерации и внесении изменений в отдельные законодательные акты Российской Федерации: федерал. закон от 13 июля 2015 г. N 224-Ф3 // Собр. законодательства Рос. Федерации. 2015. N 29 (часть I). Ст. 4350. 
2. Гражданский кодекс РФ, Земельный кодекс РФ; О контрактной системе в сфере закупок товаров, работ, услуг для обеспечения государственных и муниципальных нужд: федерал. закон от 5 апреля 2013 г. N $44-$ Ф3 // Собр. законодательства Рос. Федерации. 2013. N 14. Ст. 1652; О концессионных соглашениях: федерал. закон от 21 июля 2005 г. N 115-Ф3 // Собр. законодательства Рос. Федерации. 2005. N 30 (часть II). Ст. 3126 и другие.

3. Об утверждении формы предложения о реализации проекта государственно-частного партнерства или проекта муниципально-частного партнерства, а также требований к сведениям, содержащимся в предложении о реализации проекта государственно-частного или проекта муниципально-частного партнерства: постановление Правительства РФ от 19 декабря 2015 г. N 1386 // Собр. законодательства Рос. Федерации. 2015. N 52 (часть I). Ст. 7611; Об утверждении Методики оценки эффективности проекта государственночастного, проекта муниципально-частного партнерства и определения их сравнительного преимущества: приказ Министерства экономического развития РФ от 30 ноября 2015 г. N 894. Режим доступа: URL. http: www.pravo.gov.ru

4. Об инвестициях и государственно-частном партнерстве в Пензенской области: закон Пензенской области от 30 июня 2009 г. N 1755-ЗПО // Ведомости Законодательного Собрания Пензенской области. N 16(90).

5. О Положении «О муниципально-частном партнерстве в Сосновском муниципальном районе»: решение Собрания депутатов Сосновского муниципального района Челябинской области от 20 сентября 2017 г. N 327; Об утверждении Положения об участии муниципального образования Чаплыгинский муниципальный район Липецкой области в проектах муниципально-частного партнерства: решение Совета депутатов Чаплыгинского муниципального района Липецкой области от 28 августа 2015 года № 157 // Раненбургский вестник. 2015. 10 сентября.

6. Закон о государственно-частном партнерстве: руководство по применению. URL: www.pppi.ru/content/ upravlenie-sferoy-gchp-1

7. государственно-частном партнерстве в Томской области: закон Томской области от 17 декабря 2012 г. N 234-О3. Интернет-портал правовой информации. URL: http:// www.pravo. gov.ru

8. О внесении изменений в статьи 7 и 33 Федерального закона «О государственно-частном партнерстве, муниципально-частном партнерстве в Российской Федерации и внесении изменений в отдельные законодательные акты Российской Федерации: федеральный закон от 27 июня 2018 г. N 165-Ф3 // Собр. законодательства Рос. Федерации. 2018. N 27. Ст. 3948.

9. О внесении изменений в статью 4 Федерального закона «О концессионных соглашениях» и статью 7 Федерального закона «О государственно-частном партнерстве, муниципально-частном партнерстве в Российской Федерации и внесении изменений в отдельные законодательные акты Российской Федерации»: федерал. закон от 29 июля 2018 г. N 261-Ф3 // Собр. законодательства Рос. Федерации. 2018. N 31. Ст. 4850.

10. О внесении изменений в отдельные законодательные акты Российской Федерации: федерал. закон от 29 июня 2018 г. N 173-Ф3 // Собр. законодательства Рос. Федерации. 2018. N 27. Ст. 3956.

11. Там же.

12. О внесении изменений в постановление Правительства Ульяновской области от 11.09.2013 N 37/416-П: постановление Правительства Ульяновской области от 21 октября 2016 г. N 24/492-П. Интернет-портал правовой информации. URL: http://www.pravo.gov.ru

13. Об утверждении порядков межведомственного взаимодействия и координации деятельности исполнительных органов государственной власти Липецкой области при подготовке и запуске проектов на основе государственно-частного партнерства и концессионных соглашений: Распоряжение Администрации Липецкой области от 10 октября 2016 г. N 499-р. Опубликовано не было.

14. О государственно-частном партнерстве в Томской области: закон Томской области от 17 декабря 2012 г. N 234-O3. Интернет-портал правовой информации. URL: http://www.pravo. gov.ru

15. Создание Республиканского центра детского и молодежного инновационного творчества в городе Ижевске (Удмуртская Республика). URL: http://invest-lipetsk.ru/public/uploads/(2018_04_04)_Luchshie_praktiki_2017. pdf

16. Сазыкина С.А. Развитие государственно-частного партнерства на основе контракта жизненного цикла: автореф. дис. ... канд.эконом.наук. Белгород, 2016. С. 13.

17. Об определении случаев заключения контракта жизненного цикла: Постановление Правительства РФ от 28 ноября 2013 г. N 1087 // Собр. законодательства Рос. Федерации. 2013. N 49 (часть VII). Ст. 6430.

18. Сазыкина С.А. Развитие государственно-частного партнерства на основе контракта жизненного цикла: автореф. дис. ... канд.эконом.наук. Белгород, 2016. С. 30. 